\title{
Las aguas mineromedicinales del Monasterio de Piedra, Nuévalos (Zaragoza)
}

\section{Mineral-Medicinal Waters at the Monasterio de Piedra, Nuévalos (Zaragoza)}

\author{
PILAR Bosqued LacambRA*
}

\begin{abstract}
RESUMEN
El monasterio de Piedra, situado en Nuévalos, provincia de Zaragoza, fue monasterio cisterciense hasta 1835, fecha en la que fue desamortizado. Vendido en pública subasta, lo compró Pablo

Muntadas Campeny y, a su muerte, lo heredó su hijo Juan Federico, quien es el artífice del parque y la piscifactoría. En el año 1869 Federico descubrió de forma casual el manantial de aguas mineromedicinales que serían conocidas como de la Peña. Después de obtener la

declaración de aguas aptas para su utilidad pública, quiso establecer en el parque un sanatorio y balneario, pero a pesar del intento, sólo logró el comienzo de su proyecto. El manantial fue oficialmente clausurado en 1932.
\end{abstract}

\section{PALABRAS CLAVE}

Monasterio de Piedra, aguas mineromedicinales, lagos, cataratas, parque y jardín románticos.

\begin{abstract}
The monastery of Piedra (Stone), sited in Nuévalos, province of Zaragoza, it was a Cistercian monastery until 1835, date when it was alienated. Sold in public auction, Pablo Muntadas Campeny bought the monastery and after his death, his son Juan Federico inherited it. Federico was the author and artificer of the wonderful park and garden and the fish hatchery. In 1869 he discovered by chance the spring of the minero-medicinal water, that were called as spring of the Peña (Rock). After the statement of the spring water as capable to use by public, Federico wanted do in the park a Sanatorium and watering place, but despite the intention, he did only the beginning of the project. The spring was officialy closed in 1932.
\end{abstract}

\section{KEYWORDS}

Monastery of Stone, mineral and medicinal water, lakes, water falls, romantic park and garden.

\footnotetext{
* Doctorando del Departamento de Historia del Arte. UNED.
} 


\section{EL MONASTERIO DE PIEDRA Y J. FEDERICO MUNTADAS}

El monasterio de Piedra se encuentra situado en la provincia de Zaragoza, en el término municipal de Nuévalos. Perteneció a la orden de los cistercienses y fue habitado por los monjes hasta que sufrió la desamortización de $1835^{1}$. En ésa época las aguas mineromedicinales de la Peña y muchos de los atractivos del actual parque no existían. Tras la desamortización de Mendizábal el Monasterio de Piedra y todas sus tierras fueron sacados en pública subasta. El coto redondo, parte de las tierras y el monasterio fueron adquiridos en años sucesivos por el catalán $\mathrm{Pa}$ blo Muntadas Campeny cuyo hijo, Juan Federico Muntadas Jornet, heredará sus propiedades en Aragón, entre ellas las del monasterio de Piedra.

Federico Muntadas Jornet ${ }^{2}$ nació en Barcelona el año 1826 y moriría en Piedra a los 86 años, en 1912. Tuvo una existencia larga, feliz y muy rica, dedicándose a varias actividades a lo largo de su vida. Estudió en Barcelona y Madrid, licenciándose en Filosofía y Letras y en Derecho, doctorándose en Literatura. Destacó como escritor, poeta y autor teatral ${ }^{3}$, y ejerció también como político, abogado, traductor, piscicultor, facetas todas ellas más o menos bien conocidas. Sin embargo, resulta más desconocido su intento de crear un centro mineromedicinal y fomentar un lugar en donde la gente acudiera para tomar las aguas.

Federico actuó, reformó, invirtió, modificó y, sobre todo, transformó mejorando casi todo cuanto quiso conservar. También fue el creador del primitivo parque, del acceso a la gruta del Iris, de la piscifactoría, del hotel que se localiza en las antiguas celdas de los monjes,...en fin, el alma de cuanto en esencia en el monasterio de Piedra hoy contemplamos y admiramos. $Y$ todo ello con un admirable buen gusto, respeto hacia el arte y la naturaleza y resultados brillantes.

La zona en donde se asienta el monasterio de Piedra ${ }^{4}$ refleja la aridez del paisaje aragonés de la comarca, rodeado por una vegetación rala y escasa, con abundancia de peñas y rocas. Se encuentra hundido en una hondonada, ajeno a las vistas de cuantos por ahí pasan. Si el monasterio es algo difícil de ver, resulta imposible vislumbrar el Vergel y la zona del Lago del Espejo hasta que no se está

1 Entonces, los monjes bernardos tuvieron que desalojar el monasterio y abandonar el lugar.

2 La autora de este trabajo ha estudiado la biografía de Federico Muntadas, la historia de la Piscifactoría Central del Monasterio de Piedra y está concluyendo el estudio histórico del Parque del Monasterio de Piedra.

3 Su novela más famosa fue Vida y hechos de Gil Pérez de Marchamalo, pero la más difundida y más veces reimpresa es la que escribió en 1871 para describir su propiedad: El Monasterio de Piedra. Su historia. Valles, cascadas y grutas. Leyendas monásticas, que sacó a la luz con seudónimo: Leandro Jornet. Actualmente, se continúan haciendo reediciones del libro con algunas variaciones o supresión de alguna de las partes originales. En el año 2002 se hizo la última, que es la undécima edición.

4 Está situado a unos 720 metros de altitud. 


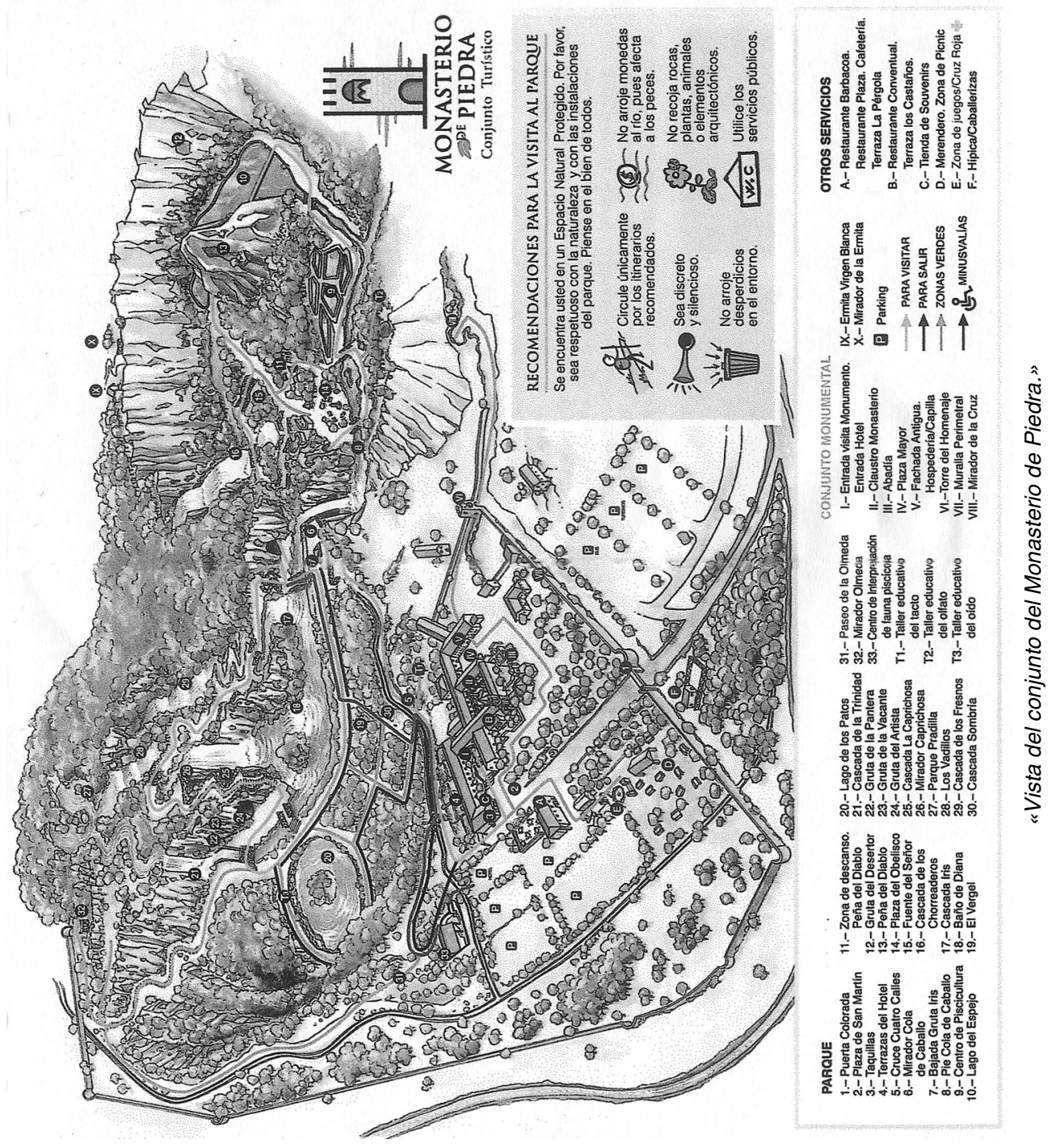


dentro del parque o arriba, allá en lo alto, junto al actual mirador de la Virgen de la Blanca, al otro lado del monasterio.

El río Piedra es el que da nombre al monasterio y lo riega, atravesando todo el recinto por el interior del parque y las antiguas huertas monacales a lo largo de unos 120 metros. Desde su entrada al parque, se precipita por cascadas hasta entrar al vergel, antigua huerta monacal, en donde discurre con apariencia natural y encajonado tras un muro, hasta que de nuevo vuelve a precipitarse por la cascada natural llamada la Cola de Caballo que, con unos 40 metros de altura, es la más alta de todas. Fuera ya de los antiguos dominios monacales continúa su curso hacia Nuévalos 5 .

El recorrido del parque del Monasterio de Piedra está cuajado de sorpresas y bellísimos rincones de cualidades estéticas y paisajistas sorprendentes. A la belleza natural del río hay que añadir el bullicio y frescor que proporcionan sus cascadas y la apacible quietud de los lagos, sobresaliendo el del Espejo. Las variadas grutas dejan en el visitante una sensación ciertamente placentera, pero ante la inquietante gruta Iris, que se descubre después de un descenso lleno de emociones, oculta tras una cortina de agua que es la que forma la Cola de Caballo, uno se queda, sencillamente, boquiabierto. La llegada al valle de la Hoz, en la zona inferior y fuera ya del recinto amurallado, depara sorpresas inimaginables. La contemplación de la cola del Caballo desde abajo, la piscifactoría y el marco incomparable de las peñas y el lago del Espejo, donde el silencio y la armonía reinan, demuestran que el paisaje creado, mejorado y embellecido por sus propietarios, resulta todo un acierto.

Al pie de la Cola de Caballo, junto al río y a la Piscifactoría Central del Monasterio de Piedra, se encuentra el espectacular Lago del Espejo o de la Peña, que está atravesado por un puente rústico y un moderno pontón que permiten pasear tranquilamente por la orilla del lago y atravesarlo, disfrutando de la especial atmósfera que ahí se percibe. A muchos de los visitantes que hoy día recorren el parque del Monasterio de Piedra seguramente les llamará la atención una choza rústica, redonda, abandonada junto al lago del Espejo y quizá algunos restos y elevaciones del terreno junto a ella. Son los restos de lo que fue el manantial de aguas conocido como aguas mineromedicinales de la Peña.

La guía de El Monasterio de Piedra que Federico Muntadas escribió ${ }^{\text {inserta }}$ una fotografía titulada «Lago del Espejo» que muestra el lugar donde se bebían las aguas de la Peña, con sus dos chozas o pequeñas edificaciones o cobertizos, una

5 En Nuévalos, se encuentra primero con el río Ortiz y después con el río Mesa, con quienes se junta en el pantano de la Tranquera y luego a alimentar las aguas del Jalón, afluente del Ebro, en dirección hacia Calatayud. El río Piedra nace a unos 1.190 metros de altitud y tiene un total de 85 kilómetros de longitud. Bleiberg, G.; Quirós LinARES, F.: Diccionario Geográfico de España. Madrid, 1960, tomo 14.

6 MuntadAs, J. F. : El Monasterio de Piedra escrito por. Zaragoza, 2002, 11. a edición, p. 92. 


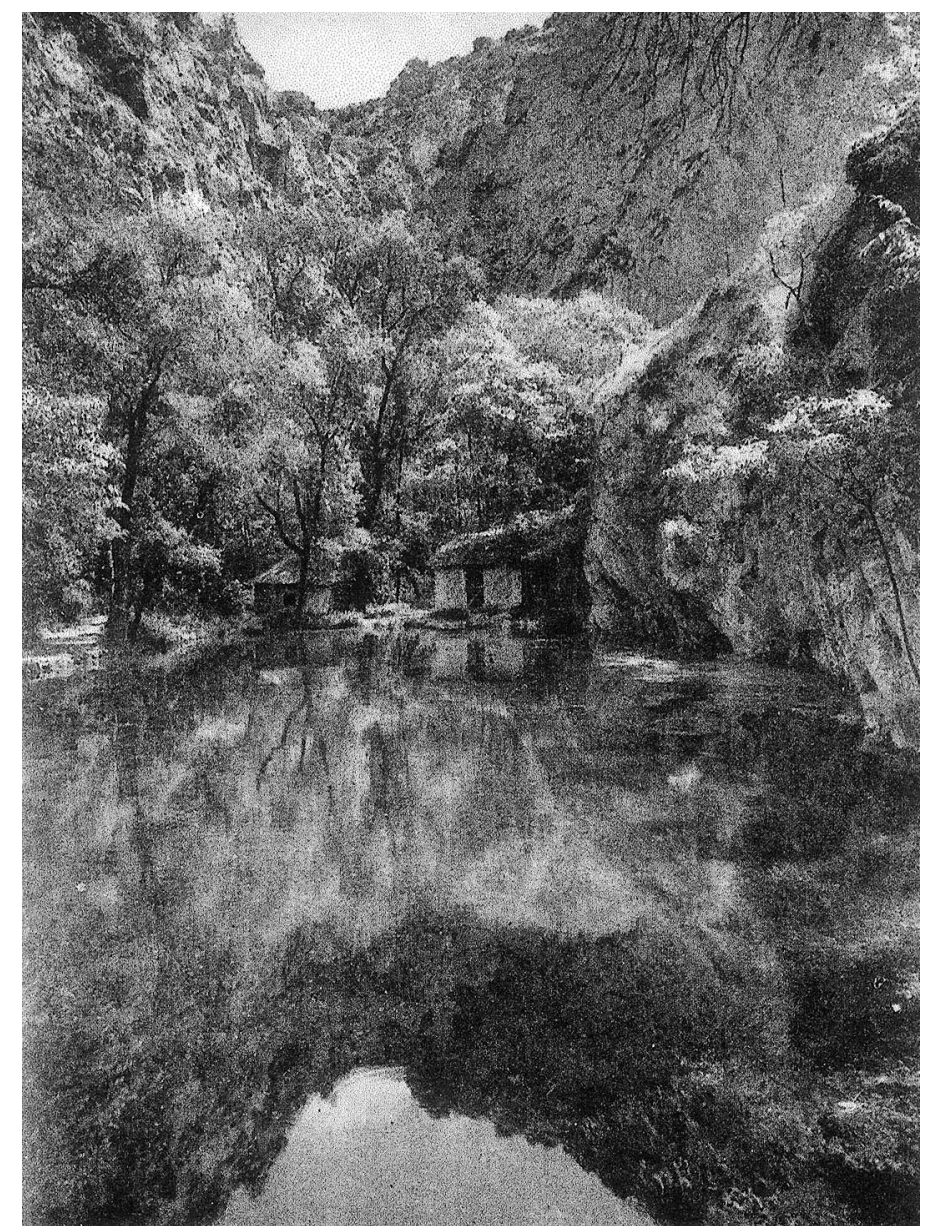

«Lago del Espejo. Al fondo, a la izquierda la caseta o pabellón rústico donde se embotellaba el agua. A la derecha, la caseta que contenía el manantial.»

es la redonda donde se embotelló agua y la otra la que albergaba la piscina o estanque donde afloraba el manantial. Hasta hace poco tiempo aún existía un letrero que indicaba el lugar donde estaba la «Fuente de la Salud» o manantial de La Peña ${ }^{7}$.

Tanto el parque, como el paisaje circundante y los edificios monacales se encuentran protegidos. El 28 de diciembre de 1945 se emite un Decreto por el que

${ }^{7}$ Puede verse una fotografía de la Fuente de la Salud publicada en el libro de F. Solsona: Balnearios Aragoneses. Pasado, presente y futuro. Zaragoza, 1992, p. 90. 
«se declara paraje pintoresco el en que está enclavado el Monasterio de Piedra, en el término municipal de Nuévalos (Zaragoza) " 8 , con su parque íntegro y las alturas colindantes en todo el perímetro que le da forma, así como sus peñascales y laderas». Por otra parte, el Monasterio de Piedra fue declarado por Real Decreto de 16 de febrero de 1983 , monumento histórico-artístico de carácter nacional ${ }^{9}$.

\section{EL DESCUBRIMIENTO DE LAS AGUAS MINEROMEDICINALES}

No hemos encontrado referencia alguna sobre la existencia o localización del manantial que ahora estudiamos que date del tiempo en el que los monjes habitaron en el monasterio de Piedra. Tampoco hemos obtenido noticia alguna de la presencia del manantial en el período que va desde 1835 hasta 1869, que será la primera fecha en donde se hace referencia al manantial. Habrá que esperar al año 1869 sencillamente por que ése va a ser el año en que se descubran.

Marcial Taboada afirma que las aguas tuvieron un descubrimiento de manera casual, y se debe al hecho de que en 1869 Federico Muntadas mandó crear un lago, que primero llamó lago de la Peña y al que luego bautizaría como el del Espejo y que, al arrancar y limpiar de maleza el lugar, los operarios encontraron el manantial de agua que hoy día se conoce como Fuente de la Salud o manantial de la Peña. Hasta entonces, el valle que hoy ocupa el lago del Espejo era un lugar salvaje lleno de carrizos, juncias y espadañas que cerraban el paso y que dejaban entrever dos o tres claros en la maleza en donde se apreciaba agua. El agua que se dejaba ver encharcada correspondería a los afloramientos de los manantiales que había en el lugar que ahora ocupa el lago del Espejo y que todavía pueden percibirse tras observar detenidamente el agua del lago, apreciándose burbujas que suben desde el fondo ${ }^{10}$.

8 Boletín Oficial del Estado. 11 de enero de 1946. Vistos los informes de la Real Academia de Bellas Artes de San Fernando y de la Comisaría General del Servicio de Defensa del Patrimonio Artístico Nacional, a propuesta del Ministerio de Educación Nacional y previa deliberación del Consejo de Ministros. El mencionado paraje quedaba bajo la tutela del Estado, ejercida por el Ministerio de Educación Nacional y al Amparo de la Ley del Tesoro Artístico y del Decreto de 31 de julio de 1941.

9 Boletín Oficial del Estado. 18 de abril de 1983. la Dirección General de Bellas Artes, Archivos y Bibliotecas había incoado expediente el 7 de abril de 1982 a favor del Monasterio para su declaración como monumento histórico-artístico. La Real Academia de Bellas Artes de San Luis de Zaragoza, señaló en el informe emitido con arreglo a las disposiciones vigentes sobre el mencionado expediente que el citado monasterio reunía los méritos suficientes para merecer dicha declaración. La tutela del monumento quedará bajo la protección del Estado y será ejercida a través de la Dirección General de Bellas Artes y Archivos por el Ministerio de Cultura, el cual queda facultado para dictar cuantas disposiciones sean necesarias para el mejor desarrollo de ese Real Decreto.

10 Taboada, M.; Puerta, G. de la: Aguas minero-medicinales de la Peña en el monasterio de Piedra.... Madrid, 1884, pp. 5-6. Marcial Taboada era médico de baños por oposición e individuo del Real Consejo de Sanidad. Testimonio de la riqueza de manantiales que en Piedra se encuentran es la presencia de la «Fuente del Señor» que puede verse actualmente durante el recorrido por el parque. 
Daza de Campos, relata que cuando los trabajos de limpieza y roturación del terreno estaban casi terminados, encontraron «un abundante manantial, cuya frescura y pureza advirtiéronse, desde luego, ya que sus virtudes milagrosas fueran ignoradas» ${ }^{11}$. Al principio, las propiedades curativas del agua pasaron, lógicamente, totalmente desapercibidas, hasta que dos personas que sentían fuertes molestias, y que estaban teniendo una digestión difícil, bebieron las aguas y experimentaron un efecto positivo en su malestar, ya que el agua calmó sus molestias y facilitó su digestión. Por ello, comenzaron a divulgar las propiedades curativas de las aguas del manantial que acababan de beber. Poco a poco la noticia se fue extendiendo y divulgando entre los vecinos. Vinieron otras personas, comenzaron a acudir los primeros enfermos de la comarca quienes, mejorados sensiblemente de sus dolencias, continuaban pregonando su benéfico uso. Los lugareños dieron un primer nombre a las aguas del manantial, y le llamaron «Fuente de la Salud ${ }^{12}$. Cada vez la afluencia de visitantes era más numerosa y así, desde 1869 hasta 1871, continuaron viniendo gente de varios lugares hasta que el genial Federico Muntadas, su propietario, dándose cuenta del nuevo «tesoro» que tenía en su propiedad, tomó la «resolución de que la ciencia comprobase los efectos que el vulgo atribuía al saludable manantial, pedir, acreditadas sus virtudes, la oportuna declaración de utilidad pública y montar un suntuoso establecimiento á la altura de los mejores entre los análogos del extranjero» ${ }^{13}$.

Como no podía ser de otra manera, y estando obligado por ley a actuar de manera determinada ${ }^{14}$, Federico Muntadas mandó analizar el agua y comenzó a imaginar cuanto podría hacer en el lugar. Cambió el nombre de «Fuente de la Salud» por el de «Aguas de la Peña», quizá más acorde con el espectacular paisaje que le rodea ${ }^{15}$. Un paisaje idílico, romántico y silencioso lleno de encanto y belleza natural. En la orilla que recorre el monte opuesto a la Peña del Diablo se encuentran los pozos más importantes. Toda esa orilla «rezuma» agua, y es por donde sale la mayoría del caudal, sin que esto se perciba apenas en superficie.

11 Daza de Campos, A.: Recuerdos del Monasterio de Piedra. Zaragoza, 1891, p. 40. Arturo Daza de Campos sería médico-director del establecimiento de aguas mineromedicinales de la Peña en la temporada de 1889 .

12 Idem, p. 41. La «Fuente de la Salud» ha estado hasta hace pocos años localizada como tal en Piedra, aunque hoy día ya no se indica su localización con letrero alguno.

13 Ibidem, p. 41.

14 El 11 de marzo de 1868 Luis González Bravo, Ministro de la Gobernación, había aprobado el Reglamento Orgánico para los establecimientos de aguas minerales por el cual nadie podrá abrir al público en lo sucesivo ningún establecimiento de aguas minero-medicinales sin la autorización correspondiente que conllevaba la previa autorización y declaración de utilidad pública. Se publicará en el Boletín Oficial de la Provincia de Zaragoza, n. ${ }^{\circ} 76$ a 82, del 12 a 23 de mayo de 1868.

15 Posteriormente se le volvería vulgarmente a llamar Fuente de la Salud, en cualquier caso, se le conoce por los dos nombres. El nombre de Fuente de la Salud, o similar, era utilizado con mucha frecuencia para bautizar aguas minerales o lugares balnearios. Así se denominaba también una fuente localizada en Zaragoza; quizá por ello Muntadas tuvo que cambiar el nombre y diferenciar el manantial de otros. 


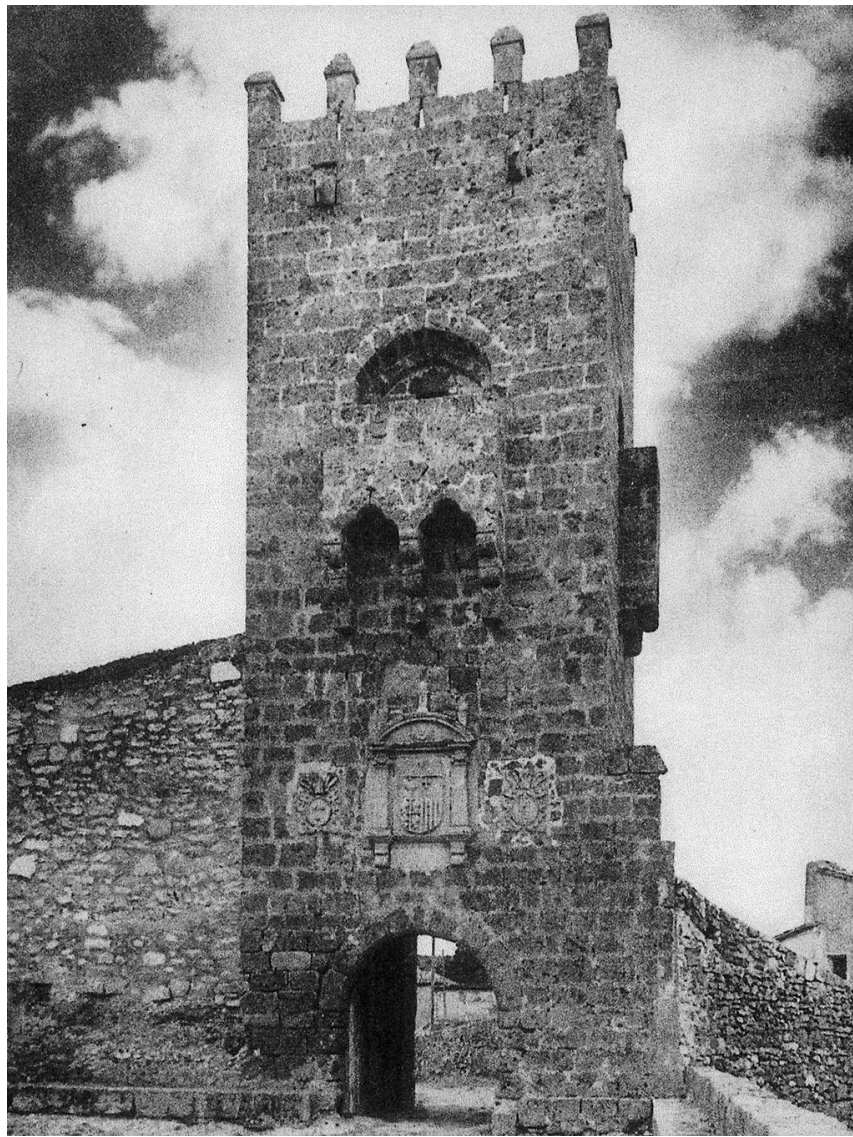

«Torre del Homenaje».

El lago tiene el fondo del terreno natural, con una profundidad media de unos 60 ó 70 centímetros y una mínima profundidad de unos 30, mientras que el pozo más importante del Lago del Espejo tiene unos 3 metros de profundidad. Las cualidades de espejo que se producen en el lago se deben en gran parte a las ovas, esto es, un conjunto de hierbas de color verde intenso ${ }^{16}$. Al encanto paisajista del lugar hay que añadir la presencia abundante de animales. Además de las truchas y otras especies piscícolas, se suman los depredadores más importantes de la cercana piscifactoría. Sin olvidar el silencio.

16 Al lago del Espejo se le debe realizar el corte de ova o hierba unas 3 ó 4 veces al año, sobre todo en la época de primavera y verano que es cuando más crece la hierba. Por su intensidad y tonalidad las ovas presentan una apariencia de artificialmente pintadas. 


\section{ANÁLISIS Y UTILIZACIÓN. INSTALACIÓN Y USOS}

En febrero de 1871 el catedrático de la Facultad de Farmacia de la Universidad de Barcelona Vicente Munner realizó a petición de Federico Muntadas un análisis cualitativo de las aguas, entonces bautizadas por su propietario como Agua de la $P e n ̃ a$, por medio del cual indica que "constituye la base de los principios minerales del agua de la Peña el carbonato de cal que se halla disuelto en ella a beneficio del ácido carbónico, formando bicarbonato. Contiene además, ligera pero sensible cantidad de magnesio e indicios de sosa, óxido de hierro y sílice» ${ }^{17}$.

La primera descripción completa del sitio donde se encuentra el manantial es de 1871, cuando el propio Juan Federico Muntadas publica bajo seudónimo su obra sobre el Monasterio de Piedra. Allí, Muntadas nos indica cómo se accedía al lugar desde las dependencias del Monasterio y qué es lo que había en el lugar donde se localizaba el manantial ${ }^{18}$.

Primero era necesario bajar al Vergel y llegar hasta la cascada Iris y, desde ahí, subir hacia la cascada de los Fresnos bajos, donde al poco se enlazaba con otro camino que, rodeando la falda del monte, conducía hasta el valle de la $\mathrm{Hoz}^{19}$. Hacia la mitad del camino y de la cuesta se encontraba la cascada llamada de los Salmones ${ }^{20}$ que se dividía en tres brazos que se juntaban en un puente del camino y que después se extendían precipitándose por entre la maleza y los árboles. El camino seguía descendiendo hasta llegar a la Peña del Diablo, donde había una pared que cerraba el paso y que se levantaba desde la peña del Diablo hasta el pie de la montaña de la Lastra que se encontraba enfrente. Se traspasaba la puerta y se accedía a la zona del lago de la Peña ${ }^{21}$, pero antes de llegar al lago, dice Muntadas, existe una plazoleta y en el centro de la misma fluye el agua del primer manantial ${ }^{22}$ al cual, añade, que "se le atribuyen virtudes medicinales, especialmente para las afecciones del estómago». Termina describiendo el lugar diciendo que el manantial está contenido en una pequeña piscina con varios bancos situados bajo la sombra de unos fresnos ${ }^{23}$.

17 Taboada, M.; Puerta, G. de la: Op. cit. p. 6.

18 Excepto las dos primeras ediciones realizadas en vida de su autor y en las que se utiliza el seudónimo (1871 y 1876), las demás incluyen el verdadero nombre del autor entre paréntesis $(1926,1961$, 1966, 1969, 1972, 198..., s.f.) o sólo el nombre sin el seudónimo (1995 y 2002).

19 Esta vía de acceso en la actualidad no existe.

20 En aquel entonces la piscifactoría criaba salmones que había traído desde Huningue.

21 En 1871, el actual Lago del Espejo todavía se llamaba con su original y primer nombre de Lago de la Peña. También se le conocerá como Lago del Silencio, aunque normalmente se le diga Lago del Espejo.

22 Conviene recordar que en el lugar donde se crea el lago hay varios manantiales o surgideros de agua, aunque uno de los principales sea, precisamente, éste.

23 JORNET, L.: El Monasterio de Piedra. Su historia. Valles, cascadas y grutas. Leyendas monásticas. Madrid, 1871, pp. 56-59. 
De esta manera, sabemos que en el mismo año que se hicieron los primeros análisis del agua, y una vez terminado de construir el lago y de acondicionar el lugar, se había creado ya una plazoleta, esto es, una zona abierta y despejada, con una pequeña piscina descubierta o estanque en la que fluía el manantial y que se habían instalado unos bancos para que las personas que fueran a beber el agua pudieran hacerlo más cómodamente. Es éste el primer estado del lugar. Muntadas afirma, que la gente del lugar que acudía a beber de manera espontánea hasta el manantial, así como los visitantes y turistas que, atraídos por el Monasterio de Piedra, sus cascadas y parque, habían probado el agua, terminaban todos diciendo que las aguas tenían propiedades benéficas e incluso medicinales, sobre todo para las dolencias estomacales. No es de extrañar, y nada más natural, puesto que éstas actuaban a manera de bicarbonato.

También en el año 1871 acude a Piedra desde Alhama de Aragón el doctor Tomás Parraverde, quien al firmar en el álbum de firmas destaca «el gran solaz que este sitio encantador y poético ofrece a los enfermos que allí concurren» ${ }^{24}$.

Tenemos muchas referencias sobre las aguas en las fechas inmediatamente posteriores. Así, por ejemplo un tal Manuel Fernando Martín dice que ahí, junto a la Fuente de la Salud, «luce siempre la luz siempre crepuscular del Purgatorio» y que en el lago «hay una miniatura de los cielos» 25 .

Víctor Balaguer visita el Monasterio de Piedra y redactará un libro sobre el Monasterio de Piedra que publica en 1882. En él dice que desde la cascada Iris se subía a la cascada de los Fresnos y desde ahí se podía «tomar una senda ${ }^{26}$ que se abre á la derecha, la cual parece ir, y va efectivamente, como en demanda de bajar al valle» de la Hoz, hacia el que "se desciende á él siguiendo á veces unas cómodas rampas de suavizadas pendientes, y otras bajando por escaleras abiertas en la peña y que en los sitios más peligrosos están provistos de rústicas pero seguras barandillas». Añade Balaguer que a mitad del camino se encuentra una cascada llamada de las truchas, y que antes se había llamado de los salmones, y que la cascada se divide en tres brazos que se subdividen en muchos riachuelos que, por el murmullo de sus aguas han llamado Chorreaderos. Desde ahí se continúa bajando hasta encontrarnos a los pies de la peña del Diablo ${ }^{27}$.

${ }^{24}$ Archivo privado M.P. Tomás Parraverde era el médico Director de los cercanos e importantes baños de Alhama de Aragón. A finales del siglo XIX el viaje hasta el monasterio de Piedra podía hacerse por ferrocarril desde Madrid o Zaragoza hasta Alhama de Aragón y desde allí los carruajes transportaban a los viajeros en 2 horas hasta el monasterio de Piedra. Una de las actividades y de los atractivos para los que acudían a tomar las aguas a Alhama de Aragón era, precisamente, acercarse en excursión hasta el monasterio de Piedra y recorrer el parque y los edificios monacales.

25 Archivo privado M.P. Manuel Fernando Martín visita Piedra el 16 de septiembre de 1878.

${ }^{26}$ La senda que conducía desde el Vergel hasta el valle de la Hoz era idéntica a las otras sendas o caminos que Federico Muntadas había creado para recorrer la parte alta del parque.

27 Balaguer, V.: Guía del viajero en Piedra. Barcelona, 1882, pp. 115-118. Víctor Balaguer visitará Piedra en 1880 y un año más tarde, en septiembre de 1880, redactará el prólogo de su obra. 
Al fondo, continúa Balaguer, se ve una pared que va desde la montaña a la roca del Diablo. En la pared, una puerta y, tras pasar la puerta se llega al lago del Espejo y justo delante del lago, se encuentra una plazoleta con una choza a la derecha y «una piscina donde fluye el manantial de una agua llamada de la salud, por ciertas virtudes medicinales que se le atribuyen, piscina que está rodeada de bancos de piedra y sitiales de paja que brindan al descanso bajo la sombra abundosa de unos centenarios fresnos ${ }^{28}$. Así, sabemos que en el año 1882 el lugar estaba sensiblemente mejorado. Balaguer dice que se habían construido bancos de piedra y colocado sitiales de paja, pero conviene destacar la presencia de la choza redonda, que se encuentra en la plazoleta, a la derecha.

Por otra parte, el doctor Fábregas, escribe el 17 de agosto de 1881 que le causa pena el advertir que «no se ven por este sitio el sin número de pacientes que divagan de un punto a otro de estaciones termales la mayor parte sin resultado alguno, siendo así que este sitio no sólo tiene lo bello, sino que también lo útil para esa clase de enfermos". Añade algo más optimista, vaticinando y diciendo que a pesar de ello «la verdad se abre paso y ello será»29. Fábregas imaginaba lo mismo que Federico Muntadas y que el lugar ofrecía posibilidades para acoger un centro balneario importante. Un año más tarde, a principios del mes de agosto de 1882, el doctor Vicente visita el Monasterio de Piedra y escribe: «hay una cosa que como médico me llama la atención, y es el aire purísimo y el suelo seco que reclama el enfermo anémico, el convaleciente y el que necesita baños de agua fría que puedan reemplazar los baños de mar, que en personas hepáticas, sobre todo, serían nocivos»30.

Daza de Campos afirma que el deseado expediente de incoación para obtener la declaración de utilidad pública quedó interrumpido al partir hacia el extranjero $\mathrm{Fe}$ derico Muntadas, pero que se reemprendió en 1882, cuando se comenzó a mover de nuevo el asunto ${ }^{31}$.

Así, en 1882, el catedrático de Química de la Facultad de Farmacia de Madrid don Gabriel de la Puerta, realiza un análisis de las aguas ${ }^{32}$. El doctor Genaro Ca$\operatorname{sas}^{33}$ dice a la vista del análisis precedente que las aguas eran útiles «en toda clase de dispepsia, ó malas digestiones con flatulencias [...] indicadísimas en la litiasis ó mal de piedra, en la colelitiasis ó cólicos hepáticos», así como otras indicaciones y observaciones ${ }^{34}$.

28 Idem, pp. 118-119.

29 Archivo privado M.P

30 Idem.

31 Daza de Campos, A.: Op. cit. p. 46.

32 Tabonda, M.; Puerta, G. de la: Op. cit. pp. 6-7. Gabriel de la Puerta era al mismo tiempo Miembro de la Real Academia de Ciencias y de Medicina y Consejero de Sanidad.

33 Que entonces era Decano de la Escuela de Medicina de Zaragoza.

34 Taboada, M.; Puerta, G. de la: Op. cit. pp. 7-8. 
El 1 de enero de 1883 el doctor Gabriel de la Puerta, presenta el análisis químico cualitativo y cuantitativo de las aguas minero-medicinales de la Peña, propiedad de Federico Muntadas. Entre otras cosas, afirma que el agua es incolora, transparente, de sabor agradable y sin olor ninguno y que cuando se agita en un vaso se desprenden burbujas de gas. Tiene una temperatura media de $15^{\circ}$ centígrados y un caudal de 18 litros por minuto. Refleja un análisis con unas cifras similares a las del doctor Casas, y como conclusión a su completo informe el doctor Gabriel de la Puerta afirma que «atendiendo á la composición química de estas aguas, pueden clasificarse como Aguas bicarbonatadas frías débilmente ferruginosas» 35 .

En la sesión del 3 de abril de 1883 de la Diputación Provincial de Zaragoza se dice que examinados varios expedientes se acuerda aprobar definitivamente los acuerdos tomados, entre ellos el de informar «favorablemente sobre el expediente incoado por Don Federico Muntadas en solicitud de que se declaren de utilidad pública unas aguas minero-medicinales en finca de su propiedad» ${ }^{36}$.

El 10 de mayo de 1883 se nombra al doctor Marcial Taboada para que pase al monasterio de Piedra «para examinar la naturaleza, yacimiento, clasificación, caudal y condiciones de explotación y de aplicación» de las aguas llamadas «Fuente de la Peña» y redacte informe sobre las mismas. El motivo era que el propietario Federico Muntadas había solicitado la declaración de utilidad pública con arreglo a lo dispuesto en el artículo $7^{\circ}$ del reglamento de baños y aguas minerales que estaba vigente ${ }^{37}$. Tres días más tarde, el 13 de mayo de 1883, Taboada pasó por Piedra comprobando y observando todo lo necesario ${ }^{38}$.

Taboada redactará un extenso y completo informe en el cual dice que el lugar donde brotan las aguas está en el valle de la Hoz, en una cañada en dirección Norte a Sur de unos 20 ó 25 metros de ancho limitado al norte por el Cerro de las Palomas de unos 90 metros de altura, al Oeste por el monte de la Lastra de unos 115 metros de altura, al Este por la Peña del Diablo de 85 metros de altura, y con esos cierres monumentales, allí, al pie de la montaña de la Lastra, «brota, emerge y se halla encerrada en sencillo brocal de piedra caliza, de forma oval, y de 0,30 metros de altura, la Fuente de la Peña [...] con cauce desahogado en su frente norte, que desagua con muy ligero desnivel en el Lago, cuyas tranquilas aguas discurren por un trayecto de 200 metros en dirección norte-noroeste ocupando casi por completo

35 Taboada, M.; Puerta, G. de la: Op. cit. pp. 13-21.

36 Archivo Diputación Provincial, Zaragoza. Actas, libro 49.

37 Taboada, M.; Puerta, G. de la: Op. cit. p. 23. Marcial Taboada fue nombrado por la Dirección General a propuesta del Consejo de Sanidad.

38 Dejó escrito en el álbum de firmas que se encuentra en Piedra la siguiente dedicatoria: « ¡Oh Piedras, Piedras...! Quien te encontrara en su camino! 13 mayo 83. Marcial Taboada». Archivo privado M.P. 
la cañada y el valle, rodeado de encantadoras orillas, poéticos sauces y deliciosas sombras que convidan á la tranquilidad, al reposo y la meditación [...]». Añade que existe una plazoleta a cuya derecha se encuentra una choza rusa ${ }^{39}$. A la izquierda, «bancos de piedra y sillas rústicas [...] un poco más allá la pequeña piscina de la Fuente». Termina la descripción diciendo que todo se halla bajo el follaje de los álamos, y que por delante se puede observar el lago y las rocas y montañas que encierran el sitio ${ }^{40}$. Deduce que las aguas «corresponden á las bicarbonatadas cálcicas-frías-variedad ferruginosa del anuario oficial»». Describe las propiedades y dice que son aptas para múltiples aplicaciones e indicaciones y que las condiciones exteriores que rodean al manantial contribuyen a la reconstitución de los pacientes ${ }^{41}$. Taboada se había dado cuenta del enorme valor terapéutico del entorno paisajístico del lugar y del beneficio que un parque tan variado y sumamente placentero podía proporcionar a los enfermos. En pleno invierno, y con una temperatura exterior de unos once grados centígrados, el manantial brota a una temperatura de un poco más de doce grados.

El 13 de junio de 1883 se emite una Real Orden por la que el Rey, conforme el dictamen del Real Consejo de Sanidad, declara como de utilidad pública las aguas del manantial de la Peña, que quedaban clasificadas como «bicarbonatadas, cálcicas, frías: variedad ferruginosa». Gabriel de la Puerta explicaba en su estudio que las aguas analizadas y estudiadas eran agua en sí y por sí, su modo de aplicación y las circunstancias exteriores ${ }^{42}$. Se añade que están especialmente «indicadas a los que padecen dispepsias, anemia, afecciones hepáticas y nerviosismo „43. Tal y como era el deseo de Federico Muntadas, quedaba legalmente aprobada la utilización y explotación con fines medicinales de las aguas mineromedicinales de la Peña en su propiedad. Se abría así un período lleno de esperanzas e ilusiones y con unas perspectivas de explotación halagüeñas y optimistas. El futuro depararía otra cosa.

39 Se refiere a la choza o caseta redonda que aún permanece en el lugar.

40 Taboada, M.; Puerta, G. de la: Op cit. pp. 24-25. Desaparecidas la piscina, los bancos y las sillas rústicas, pero no así la choza rústica o rusa, el lugar se presenta en la actualidad exactamente lo mismo. Se respira el mismo aire de tranquilidad. Se percibe idéntica belleza.

41 Idem, p. 28.

42 Tabonda, M.; Puerta, G. de la: Op.cit. p. 28.

43 Gaceta de Madrid, n. ${ }^{\circ}$ 165, 14 junio, 1885. Para obtener la declaración de utilidad pública del establecimiento que Federico Muntadas tenía en propiedad y la autorización necesaria para hacer uso público de las aguas, Federico tuvo que presentar ante el Gobernador de la Provincia el expediente necesario en el que se debía incluir la instancia, plano en escala 1/500 del terreno con las dependencias que el establecimiento había de tener con inclusión de los edificios existentes y los que se piensan construir, memoria histórico-científica, análisis químico cualitativo y cuantitativo y certificación del alcalde especificando número de forasteros y de personas del pueblo que frecuentan los baños. Todo ello acompañado de un informe previo del Subdelegado de Medicina. Puede leerse publicado en el Boletín Oficial de la provincia de Zaragoza n. ${ }^{\circ} 77$ a 82, del 12 al 23 de mayo de 1868. 


\section{LA EXPLOTACIÓN BALNEARIA DE LAS AGUAS MINEROMEDICINALES DE LA PEÑA DEL MONASTERIO DE PIEDRA (1883-1932)}

El 13 de junio de 1883 el Ministro de la Gobernación ${ }^{44}$ publica la Real Orden conforme con el dictamen emitido por el Real Consejo de Sanidad por la cual dispone que según el expediente instruido a instancia de Federico Muntadas solicitando la declaración de utilidad pública de las aguas minero-medicinales del manantial de la Peña (Monasterio de Piedra) que brotan en terrenos de su propiedad y a la vista de haber presentado todos los documentos previstos para ello y "considerando que el dueño del balneario dispone de medios suficientes con que poder proporcionar cómodo alojamiento á los enfermos", dispone que se declaren de utilidad pública las aguas bicarbonatadas cálcicas frías, variedad ferruginosa del manantial de la Peña, que emergen en propiedad de D. Federico Muntadas» y le autorizan para que abra el establecimiento al servicio del público en la temporada que irá del 15 de mayo al 15 de octubre ${ }^{45}$.

La Real Orden especifica igualmente que el propietario debe proceder a ejecutar una serie de obras indispensables en la estructura para la captación del manantial, que brotaba por distintos lugares, teniendo especial cuidado en no realizar desmontes ni provocar nuevos afloramientos ${ }^{46}$. Se intentaba con ello evitar la contaminación del agua del manantial con las aguas de los demás surgideros y del propio Lago del Espejo.

Igualmente, se exige la creación de un muro que proteja la fuente o manantial que deberá además cubrirse con un quiosco que permita a los enfermos resguardarse de los inesperados cambios de la atmósfera, añadiendo que la construcción más adecuada sería la de una galería ${ }^{47}$. También se pide que se realice una completa estación balneoterápica, en la que no deberían faltar «plantaciones de árboles que proporcionen sombra bastante á evitar á la concurrencia la molestia que produce la acción directa del sol, y se mejoren, por último, los caminos que enlazan á aquel establecimiento con el Monasterio de Piedra» ${ }^{48}$.

44 Pío Gullón.

45 Gaceta de Madrid, n. ${ }^{\circ}$ 165, 14 de junio de 1883.

46 Gaceta de Madrid, n. ${ }^{\circ} 165,14$ de junio de 1883.

47 Idem. Hasta el momento, el agua del manantial estaba a merced de las inclemencias del clima y, al estar al aire libre y sin protección alguna sufría todo tipo de incidencias tales como la caída de hojas sobre el agua, polvo o presencia de animales e insectos.

48 Idem. La pequeña excursión que los agüistas debían realizar no era difícil, pero sí que fatigaba y no era la adecuada para un enfermo, dado lo escarpado del terreno y la exposición a los rayos del sol. El itinerario pintoresco y romántico que Federico ideó en un principio no serviría para la utilización de las aguas del manantial con fines medicinales. 
El primer Médico Director del balneario del Monasterio de Piedra don Nicasio Mariscal afirma ${ }^{49}$ que la temporada de 1883 no había sido completa ya que la declaración de utilidad pública se había realizado hacia la mitad de esa misma temporada, es decir, en junio de 1883. Mariscal elaboró un informe en octubre de 1883 en el que describe algunos "casos de curación notables» 50 .

Uno de los requisitos que se pedían era que el propietario debía mejorar los caminos que comunicaban el hotel del monasterio de Piedra con el manantial ${ }^{51}$. Muntadas mandó ese mismo año ${ }^{52}$ construir un túnel de unos 33 metros de longitud que eliminó gran parte de las escaleras que se habían abierto con anterioridad para recorrer el parque por la parte superior y que era un pintoresco camino lleno de escaleras, rampas y puentes ${ }^{53}$.

La galería que se exigía para resguardar a los enfermos no se construirá, pero sí que se había construido un ancho pilón que rodeaba el punto por donde surgía el manantial. El pilón, o pequeña piscina, quedaba cubierto, tal y como se exigía, por un cobertizo de aspecto rústico ${ }^{54}$. Se pide también que se realice una estación balneoterápica, y plantaciones de árboles que proporcionen sombra a los concurrentes. Lo primero no se realizará nunca, al menos no hemos encontrado hasta el momento vestigios algunos, mientras que las plantaciones de árboles sí que se realizarán ${ }^{55}$.

En la Memoria que el doctor Amaro Masó Bru presenta el 15 de diciembre de $1884^{56}$ se refleja una crítica acerca del establecimiento, dura y realista, en la que termina su autor concluyendo «que aquella estación hidrológica no merece el título de tal, pues ni se ha hecho la instalación balneoterápica reclamada por el Dr. Taboada, ni se ha marcado la temporada indicada, ni el manantial reúne las condiciones que justifiquen su título oficial, ni aun concurrentes, pues en los cuadros estadísticos sólo figuran cinco enfermos en toda la época balnearia»57. A pesar de

${ }^{49}$ MARISCAL, N.: Memoria anual reglamentaria de las aguas de la Peña,en el Monasterio de Piedra. Ateca, 1883.

50 TABOADA, M.; Puerta, G. de la: Op.cit. pp. 31-35. Presenta igualmente seis casos que describe con toda clase de detalles, entre ellos el que corresponde a la hija de los propietarios, Pilar Muntadas

51 Se debía aliviar la marcha de los agüistas y acortar la distancia existente entre el manantial y el puente que se levanta a los pies de la cascada Iris.

52 Taboada lo refleja ya en su obra de 1884 y dice en la página 9 que el túnel acababa de abrirse.

${ }^{53}$ El camino que une el manantial de la Peña y los edificios del monasterio quedaba algo más accesible y acortado, sensiblemente mejorado de acuerdo a las exigencias de la Real Orden.

54 Jordana y Morera, J.: El Monasterio de Piedra visto al natural. Madrid, 1885, p. 32.

${ }^{55}$ Las plantaciones se harán de manera constante y continua, cuidándose especialmente esta faceta.

${ }^{56}$ MAsó Bru, A.: Memoria anual de las aguas minero-medicinales del Monasterio de Piedra. BarceIona, 1884. Amaro Masó Bru era doctor por oposición y médico director. Fue el segundo Médico director de las aguas del Monasterio de Piedra y el primero que realiza una crítica del establecimiento. Masó marchó enfurecido y malhumorado de Piedra.

${ }^{57}$ Martínez Reguera, L.: Bibliografía hidrológica-médica española. Madrid, 1897. Tomo II, p.97 
las mejoras que Muntadas había emprendido, la adecuación del lugar era incompleta y la explotación del Monasterio de Piedra como lugar de balneario era un fracaso.

En 1891 Arturo Daza de Campos, publica una obra ${ }^{58}$ en la que define a la caseta del agua mineral como elegante, aunque califica a las dos casetas como unas chozas rústicas que quedan enclavadas entre filas apretadas de árboles. Tiene especial cuidado en advertir que a pesar de la gran cantidad de agua que hay por todas partes, procedente de las cascadas, de los lagos ${ }^{59}$, del río, del vapor de agua en suspensión y demás, el ambiente es extremadamente seco y sano y que la malaria, las infecciones palúdicas y cuantas puedan asociarse a las aguas pantanosas y lugares húmedos están totalmente excluidas dada la naturaleza del terreno y la composición de las rocas ${ }^{60}$. Nos revela el nombre con el que se designaba la plazoleta en la que se encontraba el manantial: Plaza de la Salud ${ }^{61}$. Dice que la cabaña que recibe el nombre de choza rusa se utilizaba para el «taponamiento de las botellas del agua mineral que se consume en el establecimiento y de la que se destina á la venta», de manera tal que el agua se embotellaba en una caseta y se taponaba en otra ${ }^{62}$. Añade que se trata de un agua que es perfecta para utilizar como agua de mesa ${ }^{63}$. Este autor indica aquí, a nuestro modesto entender, la principal cualidad y calidad del manantial de la Peña que no era otra que la de ser perfecta para ser embotellada y bebida como agua de mesa ${ }^{64}$.

En 1892 Eduardo Ozores describe el lugar y le llama Valle del Silencio ya que, de repente, nada se oye ${ }^{65}$. Además, detalla el plan del agüista una vez instalado en el Monasterio de Piedra: para tomar las aguas, se debe bajar por la mañana, temprano, hacia el Vergel, cruzar el río por el puente junto a la cascada Iris, atra-

58 Daza de Campos, A.: Recuerdos del Monasterio de Piedra. Zaragoza, 1891.

59 Además del espectacular lago del Espejo en el valle de la Hoz, existe otro lago mucho menor en el Vergel del parque, el llamado lago de los patos, situado entre las cascadas Iris, Trinidad, Caprichosa y la Sombría.

60 DaZA DE CAmpos, A.: Op. cit., pp. 50-52. Añade que el establecimiento «que data de ayer» tiene posibilidades de competir con otros del extranjero como los de Spa, Alet y Evian, y de España como Sobrón, Marmolejo, Mondáriz, Puertollano y Ribas, o a las aguas de Lanjarón, Nanclares y Alzola en España o a las de Pougues, Condillac y Saint y Galmier de Europa lo que resulta totalmente exagerado e impreciso. En definitiva, una opinión un tanto temeraria y atrevida, ya que el establecimiento de Piedra no pasaría de ser un proyecto, un sueño condenado al fracaso.

61 Idem. p. 39.

62 Ibidem. p. 42.

63 En cursiva en el original.

64 Fernando Solsona indica que «se embotelló con el nombre de Agua de la Peña», en SolsonA, F.: Balnearios Aragoneses. Pasado, presente y futuro. Zaragoza, 1992, p. 90. La Real Orden de 17 de mayo de 1886 concedía autorización de venta embotellada de las aguas minero-medicinales que no eran susceptibles de explotarse en un establecimiento balneario y que provocaban ciertos abusos.

65 Ozores, E.: Un verano en Piedra. Impresiones y bocetos. Madrid, 1892, pp. 12-13. Eduardo Ozores fue médico director de las aguas minero-medicinales durante la temporada de 1892. 
vesar el túnel, descender junto a los Chorreaderos, llegar a la fuente, sentarse, reposar y beber dos vasos de agua «que saben a gloria». Luego, se asiste al espectáculo de ver cómo las truchas devoran la comida ${ }^{66}$ y se vuelve a subir. Se espera pacientemente la hora del almuerzo y quienes así han sido prescritos, vuelven a beber el agua de la Peña en la comida ${ }^{67}$. Sin embargo, Ozores termina su libro con una poesía escrita en el mes de mayo de 1892 dedicada a su amigo propietario y, al final, describe de forma elegante la cruda realidad que percibía:

$$
\begin{aligned}
& \text { “Yo viviré aquí contento... } \\
& \text { aunque no vengan bañistas» } 68 \text {. }
\end{aligned}
$$

No tenemos apenas referencias de las actividades balnearias de la primera década del siglo xx, a pesar de que Muntadas pasará la mayor parte de los últimos años de su vida en su propiedad del monasterio de Piedra. Tras la muerte de Federico Muntadas en septiembre de 1912 el monasterio de Piedra, el parque y las aguas mineromedicinales agonizan y el lugar se abandona un poco. Los turistas dejan de acudir con la frecuencia de antaño. La crisis económica se dejará sentir también en Piedra.

\section{EL CIERRE DEFINITIVO}

El 18 de junio de 1932 se clausura el Balneario del Monasterio de Piedra por orden de la Dirección General de Sanidad dictado en virtud del informe de la Inspección General de Sanidad. Por la misma, «se dispuso la clausura del citado Balneario por no tener las instalaciones hidroterápicas necesarias, llevándose a ejecución tal Orden no solo en el cierre del Balneario, sino que fue clausurado además y sellado el manantial de que se ha hecho mérito, enclavado dentro de la finca»69. En esas fechas, los agüistas no acudían apenas a hacer uso de las aguas como bebida a pie de manantial ni el agua se empleaba en las formas hidroterápicas propias de un balneario, tales como baños, duchas, inhalaciones, pulverizaciones, o demás. El Monasterio de Piedra, que había embotellado agua del manantial de la Peña para su consumo en la hospedería, vería así terminadas sus actividades relacionadas con las aguas minero-medicinales.

66 La piscifactoría se encuentra, como ya se ha dicho, junto al Lago del Espejo y la Peña del Diablo

67 OzORES, E.: Op. cit. pp. 18-19.

68 Idem, p. 34. podemos afirmar como cierto que la atracción por las aguas no era excesiva y que ésta se extendía sobre todo a los vecinos de la comarca que se acercaban hasta el lugar para beber y tomar el agua por su cuenta sin atender las indicaciones del médico director de los baños. Lo que sí entusiasmaba a todos cuantos acudían a Piedra era el conjunto de su naturaleza y las posibilidades del lugar.

69 Archivo privado MP. 
Sin embargo, en 1933 la propiedad del Monasterio de Piedra solicitará permiso para una nueva apertura del manantial de la Fuente de la Peña. El 25 de marzo de 1933 la Inspección Provincial de Sanidad de Zaragoza escribe al Alcalde de Nuévalos y le dice que la propiedad ha solicitado autorización para embotellar y expender embotelladas las aguas del manantial. Tras informe favorable, ya que de ello se beneficiaría la salud pública al permitirse el uso de aguas mineromedicinales declaradas de utilidad pública, la Dirección General resuelve de acuerdo con el informe acceder a lo solicitado, siempre que no se quebrante la clausura con fecha de 18 de junio de 1932 impuesta al Balneario y que se efectúen las operaciones de captación y embotellado de las aguas según las prescripciones higiénicas y legales vigentes ${ }^{70}$.

En la etiqueta de las botellas del agua de la Peña, tituladas como Aguas minero-medicinales de la Peña (Monasterio de Piedra) Aragón, entre otras cosas, podía leerse que eran «bicarbonatadas cálcicas frías variedad ferruginosa» y, en la parte correspondiente a las aplicaciones, que «estas aguas por su especial mineralización y por sus virtudes reconstituyentes están indicadas a los que padecen de dispepsias, anemia, afecciones hepáticas y nerviosismo. Por su situación topográfica y condiciones climatológicas es el Monasterio de Piedra la mejor estación estival de España para el período de convalecencia de todas las enfermedades » ${ }^{71}$. También hubo otros estudios y proyectos varios para volver a intentar embotellar agua de mesa, pero no llegó a hacerse al ser incompatible con las actividades piscícolas y turísticas del lugar.

Piedra funcionó oficialmente como balneario, es decir tuvo reconocido su manantial de manera oficial como abierto al público y como lugar en el cual se podía beber las aguas, desde el año 1883 en que fueron declaradas de utilidad pública, hasta su cierre también oficial en 1932. Es decir unos cincuenta años en los que nunca fue de verdad un lugar balneario, aunque hubiera podido serlo. Pero popularmente, el manantial se utilizó algo más, ya que como hemos dicho, se comenzó a utilizar desde su "descubrimiento" en 1869 por lo que puede decirse que las aguas del manantial fueron utilizadas y bebidas durante algo más de 60 años.

Además, el paso del tiempo, tan cruel con las cosas más bellas, ha venido en dar la razón a Federico Muntadas y al parque o jardín romántico por él creado, ya que el Monasterio de Piedra es hoy día uno de los exponentes más ricos y conocidos de la industria turística de Aragón. En la actualidad, las cosas siguen así y el manantial está sellado y no puede hacerse uso de él más que para la primitiva idea de Federico Muntadas, es decir, la de que con sus aguas se alimentara el lago del Espejo que comenzó a crear en 1869.

70 Archivo Histórico Ayuntamiento Nuévalos. Secretaría, Correspondencia. Caja 8.

71 Archivo privado P.B. 


\section{BIBLIOGRAFÍA}

BALAguer, V.: Guía del viajero en Piedra. Barcelona, 1882.

Barbastro GIL, L.: El Monasterio de Piedra (1194-1836). Ayer y hoy de la abadía cisterciense. Elche, 2000.

BleiBerg, G.: Diccionario geográfico de España. Madrid, 1960.

CAstells y BALlespí, R.: Riqueza hidrológica y climatológica de España. Madrid, 1913.

CostA, J. L. : Anuario Guía General de los Balnearios y Aguas minerales de España y Mediodía de Francia. Madrid, 1906.

Daza de CAmpos, A.: Recuerdos del Monasterio de Piedra. Zaragoza, 1891.

Guía Oficial de Balnearios y Aguas Minero.medicinales de España. Madrid, 1950

Guía oficial de los establecimientos y aguas medicinales de España. Madrid-Barcelona, 1926.

Heredia y R. JAEN, R.: Album del Monasterio de Piedra. Madrid, 1900.

JoRDANA y MORERA, J.: El Monasterio de Piedra visto al natural. Madrid, 1885.

JoRnet, L.(Muntadas, J. F.): El Monasterio de Piedra. Su historia, valles, cascadas y grutas. Leyendas monásticas. Madrid, 1871.; Madrid, 1876; Barcelona, 1926 (3. ${ }^{a}$ ed.); Barcelona, s.f. (4. ${ }^{a}$ ed.); Barce-

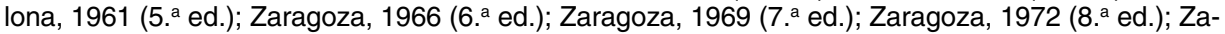
ragoza, s.f. (9. ${ }^{a}$ ed.); Zaragoza, 1995 (10. ${ }^{a}$ ed.); Zaragoza, 2002 (11. ${ }^{\text {e ed.). }}$

JUDEZ, F.: Vistas del Monasterio de Piedra. Zaragoza, s.f.

MARISCAL, N.: Memoria anual reglamentaria de las aguas de la Peña, en el Monasterio de Piedra. Ateca, 1883.

Martínez Reguera, L.: Bibliografía Hidrológica-Médica Española. tomo I, Madrid, 1892. Tomo II, Madrid, 1897.

Masó Bru, A.: Memoria anual de las aguas minero-medicinales del Monasterio de Piedra. Barcelona, 1884.

MenÉndez, C.; AleiXAndre, J. M. ${ }^{a}$ : Colección Legislativa de Baños y Aguas Mineromedicinales. Madrid, 1892.

Moreno GonzÁlez, R.: Riqueza hidrológica de Aragón y la Rioja. Zaragoza, 1966.

MUNTADAS, J. F.: Ver JORNET, L.

Muntadas Nagel, E.; Muntadas-Prim Salvadó, L.: Recuerdos y hechos sucedidos en el ex-Monasterio de Piedra desde que éste pasó a propiedad privada hacia 1840. Barcelona, 1970.

Ozores, E.: Un verano en Piedra. Impresiones y bocetos. Madrid, 1892.

PéreZ VILlamil, M.: Recuerdos del Monasterio de Piedra. Madrid, 1873.

Quadrado, J. M.: Recuerdos y bellezas de España. Aragón. Barcelona, 1844.

España. Sus monumentos y artes. Su naturaleza e historia. Aragón, Barcelona, 1886.

Rosel SAEZ, J.: Fuentes bibliográficas para el estudio de la Hidrología en Aragón. Zaragoza, 1976.

RuBıo, P. M.a: Tratado completo de las fuentes minerales de España. Madrid, 1853.

SolsonA, F.: Balnearios aragoneses. Pasado, presente y futuro. Zaragoza, 1992.

TABoAda, M.; Puerta, G. de la: Aguas minero-medicinales de la Peña en el Monasterio de Piedra. Madrid, 1884. 